\title{
Parturition and Morphological Development of Larvae and Juvenile in Hippocampus kuda from Korea
}

\author{
Gi-Seok Lee', Sung-Hun Lee², Jin Lee², Jea-Min Park³, and ${ }^{\dagger}$ Kyeong-Ho Han² \\ ${ }^{1}$ Wolchon Middle School, Suncheon 57902, Korea \\ ${ }^{2}$ Marine Technology Undergraduate, Chonnam National University, Yeosu 59626, Korea \\ ${ }^{3}$ Gyeongsangbuk-Do Native Fish Business Center, Uiseong 37366, Korea
}

\begin{abstract}
The newborn, Hippocampus kuda larvae were 6.97-8.81, standard length (SL) mm (mean $7.89 \mathrm{~mm}$ ) and mouth and anuse were open. Dorsal fin rays 15-18 and pectoral fin-rays were counted 8 and had 10-11+21 myotomes, body's bony plate ring being developed strongly in the central axis of myotomes part. 4 days after bearing, the SL was $7.02-9.47 \mathrm{~mm}$ (mean $8.24 \mathrm{~mm}$ ) and nostrils began to open. 12 days after bearing, larvae attained to $8.91-11.2 \mathrm{SL} \mathrm{mm}$ (mean $10.0 \mathrm{~mm}$ ). From this time, their unique predation habit appeared. 21 days bearing, larvae attained to 12.1-14.8 SL mm (mean $13.4 \mathrm{~mm}$ ) the and thorn of back was enlarged among the plate formed around ring. 41 days bearing, seahorses attained to 17.1-17.8 SL $\mathrm{mm}$ (mean $17.4 \mathrm{~mm}$ ) and the number of body's bony plate ring of the top of rings trunk was 11 and on the tail of them was 33-36, similar to figure of adult..
\end{abstract}

Key words : Seahorse, Hippocampus kuda, Egg, Larvae, Juvenile

\section{INTRODUCTION}

Hippocampus fish (Gasterosteiformes; Syngathidae) live mainly in shallow coastal areas with many coral reefs in temperate and tropical waters. They have a unique spawning method in which females hand over the eggs to males' marsupium in the spawning season and males give birth (Foster \& Vincent, 2004; Lourie et al., 2004). Hippocampus kuda was introduced as a new species by Bleeker in 1852, but recently Lourie et al. (1999a), it was confirmed that it was the same species as the true Hippocampus, $H$. aterremus, published by Jordan and Snyder (1901).

It is known to be distributed in India and the Pacific, Pakistan, Hawaii, Society island and the coast of Japan
(Fishbase, 2018), It is reported that there are 52 genera and 215 species in the world and 6 genera and 11 species in Korea, which belong to Syngnathidae. These, 25 species are known in Hippocampus, which is seahorse (Chyung, 1977; Myers, 1979; Vari, 1982; Kim et al., 2005), but in recent years, seahorse has been re-identified as having 32 species in seven habitat marine categories using external morphological traits and genetic traits $(12,16 \mathrm{~S}$ mtDNA) based on coastal category ecological features with limited swimming waters (Lourie et al., 1999b; Koh et al., 2004).

The demand for sea horses rapidly increased due to the use of ornamental organisms and herbal medicine materials, resulting in a tremendous decrease in resources in natural waters such as Southeast Asia due to over fishing and

\footnotetext{
Manuscript received October 20, 2018, Received in revised form November 5, 2018, Accepted November 29, 2018

$\dagger$ Corresponding Author : Kyeong Ho Han, Marine Technology Undergraduate, Chonnam National University, Yeosu 59626, Korea. Tel: +82-61-6597163, Fax: +82-61-659-7169, E-mail: aqua05@jnu.ac.kr
}

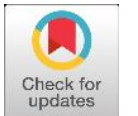

This is an Open Access article distributed under the terms of the Creative Commons Attribution Non-Commercial License (http:// creative-commons.org/licenses/by-nc/3.0) which permits unrestricted non-commercial use, distribution, and reproduction in any medium, provided the original work is properly cited. 
therefore, some species are endangered (Vincent, 1996; Lourie et al., 1999b). Since the survival rate of early fish larvae is very low as well as brood stock culture, artificial seed production is difficult, and studies on species conservation are very urgent (Scarrat, 1995; Vincent, 1996).

The coastal area of Korea where seahorses mainly live is shallow and consists of eelgrass bed. However, since the habitat is gradually decreasing due to marine pollution and coastal landfill, it is necessary to protect the habitat of sea horses which are sensitive to environmental change and have low mobility.

Studies on seahorses include studies on increased resource conservation and early life history such as mating habit (Masonjones \& Lewis, 1996), spawn behavior (Woods, 2000a; Masonjones, 2001), breeding environment and food creatures (Hilomen-Garcia et al., 1999; Payne \& Rippingale, 2000; Woods 2000b; Adams et al., 2001), H. kuda (Koh et al., 2004), H. barbouri (Choi et al., 2006a), $H$. coronatus (Choi et al., 2006b), and H. histrix (Van Look et al., 2007) etc., Koh et al. (2004) reported that the development of the philippine $H$. kuda has not been studied.

Every species of seahorses are similar in the number of dorsal fin rays, development of the body's bony plate ring, body protrusions and tail skeleton during the period of fish larvae. In the case of adult fish, the body color changes according to the environment and growth, and body protrusions fall off easily, so it is known that species are difficult to be classified morphologically with possibility of interspecific hybridization (Koh et al., 2004). Therefore, in this study, we observed the courtship, fertility behavior and larvae and juveniles of external developmental of the reproductive $H$. kuda, which were known to be $H$. aterremus in the past. Seed production and species preservation studies will be used as baseline data for taxonomic studies.

\section{MATERIALS AND METHODS}

\section{Brood stock securing and breeding}

The samples used in this study were 20 pairs of male and female H. kuda taken at Wonju Island in Goheunggun, Jeollanam-do in June 2015. After transported to the laboratory, they were placed in a glass square bath $(30 x$ $90 \times 60 \mathrm{~cm}$ ) to observe mating behavior. Temperature and salinity were maintained at $27.5^{\circ} \mathrm{C}-28.5^{\circ} \mathrm{C}$ (mean $28.0^{\circ} \mathrm{C}$ ) and 34.5-35.5 psu (mean $35.0 \mathrm{psu}$ ), respectively. Small ice shrimps (Hikari, China) were fed twice a day.

\section{Morphology of eggs and larva}

For observation of bearing, hatched males were breeding management. For observation of egg shape, hatched eggs were taken, observed and measured using a universal projector (Nikon JP V-12B, Japan) and a stereomicroscope (Nikon SMZ18, Japan). For observation of larva and juveniles morphological development, ten individuals were collected immediately after bearing and fixed in $10 \%$ of neutral formalin, and a universal projector and a stereomicroscope were used to measure the external characters up to $0.01 \mathrm{~mm}$.

\section{Breeding of larva and juveniles}

The breeding environment was the same as that of their mothers, and Brachionus plicatilis was feed from 12 to 21 days after bearing and Artemia sp. nauplius incubation larva was supplied from 21 to 41 days after bearing. After that, small ice shrimps were supplied in small quantities.

\section{RESULTS}

\section{Mating and spawning behavior}

The mating behavior of $H$. kuda is contact behavior that males and females face each other and hit the snout, and males showed continuously following actions (Fig. 1A). The female who is about to spawn projected the oviduct in the abdomen and then, the female reacted to the mating behavior of the male, and the male wound its tail of the female and swam (Fig. 1B). The male and female swiftly 


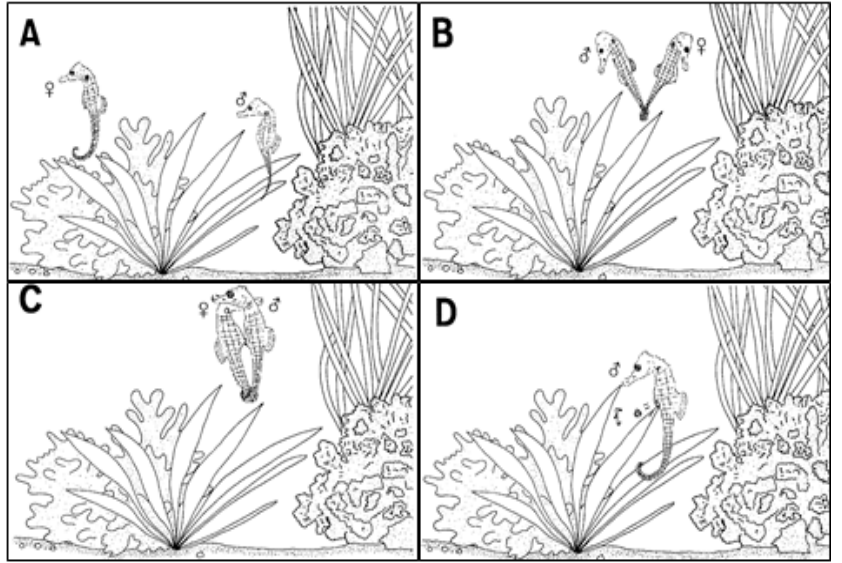

Fig. 1. Mating and spawning behavior of Hippocampus kuda. A, The male follow affection action in female; B, Female and male wind tail; $\mathrm{C}$, The female laying eggs to the belly in male; $\mathrm{D}$, The male is delivered the larvae.

swam to the top of the water with their tails winding, and they repeatedly performed the same action, and the female layed eggs by inserting its oviduct into the male's marsupium (Fig. 1C). The male that spawn protected the fertilized eggs in its marsupium and they began to hatch slightly from the 12 days after fertilization. The male marsupium was swollen over time. On the 19 and 20 days after the fertilization, the male gave birth to about 70 larvae from its marsupium with its tail wrapped around the seaweed (Fig. 1D).

\section{Amount of spawn and morphology of eggs}

The amount of spawn in H. kuda females was 112-162 (mean $143, n=10$ ), and the amount of spawn identified in the male's marsupium was $82-136$ (meane $112, n=10)$, and the eggs of the male's marsupium accommodated about $80 \%$ of the female spawn amount.

The egg shape was similar to the peanut shape, the color was orange, and the eggs had some stickiness. The male's marsupium had wrinkles on the inside of the pouch, spongeshaped epidermis and small veins were observed, and there were several eggs on the honeycomb-shaped skin tissue (Fig. 2A, B).

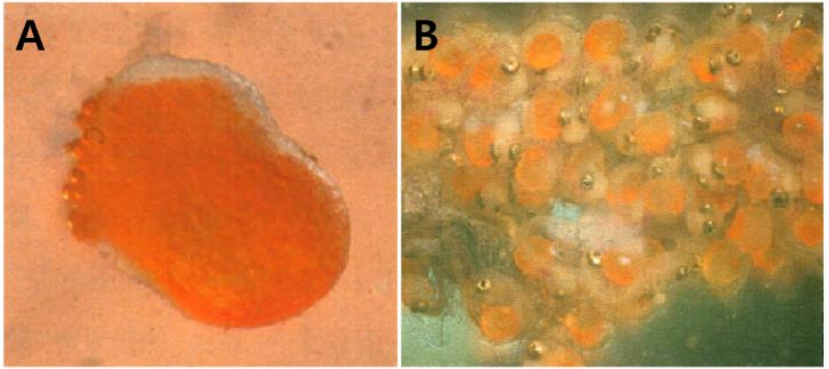

Fig. 2. Fertilized egg (A) and eggs in the brood pouch with developed slender blood vessel (B) of Hippocampus kuda.

\section{Morphology development of larva and juveniles}

Immediately after bearing of $H$. kuda, larva and juve-

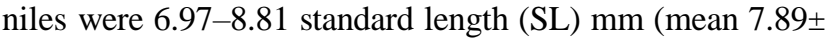
$1.30 \mathrm{~mm}, \mathrm{n}=10$ ), and mouth and anuse were open, and the fin of each part was developed. The number of fin rays is 15-18 dorsal fins and 8 pectoral fins. At head, one strong thorn was developed over the eyeball, and two thorns were developed on the gill lid, and it was observed that the thorns were split into two according to the individuals. At this time, the larvae and juveniles completely absorbed the egg yolk and the body surface part in front of the anus was transparent compared to the other body surfaces, and no chromophore was observed. The number of body's bony plate ring was $10-11+21$, and body's bony plate ring was developed around the myotomes part (Fig. 3A).

On the 4 days after bearing, larvae were 7.02-9.47 SL $\mathrm{mm}$ (mean $8.24 \pm 1.73 \mathrm{~mm}, \mathrm{n}=10$ ), the number of pectoral fins increased to 11 , their snout was elongated, and the black vesicles formed on the body surface became thicker like leaves. The nostrils began to open in front of the snout, a pair of safety thorns appeared around the eyes, and the distal end of the thorns developed inward (Fig. 3B).

On the 12 days after bearing, larvae were 8.91-11.2 SL $\mathrm{mm}$ (mean $10.0 \pm 1.61 \mathrm{~mm}, \mathrm{n}=10$ ), and the number of body's bony plate ring on the trunk was 11 , on the tail of them was 33-36. A pair of thorns were formed at the edge of the back of the head, and the shape of nostrils began to develop in a shape similar to dumbbells. The shape of the 

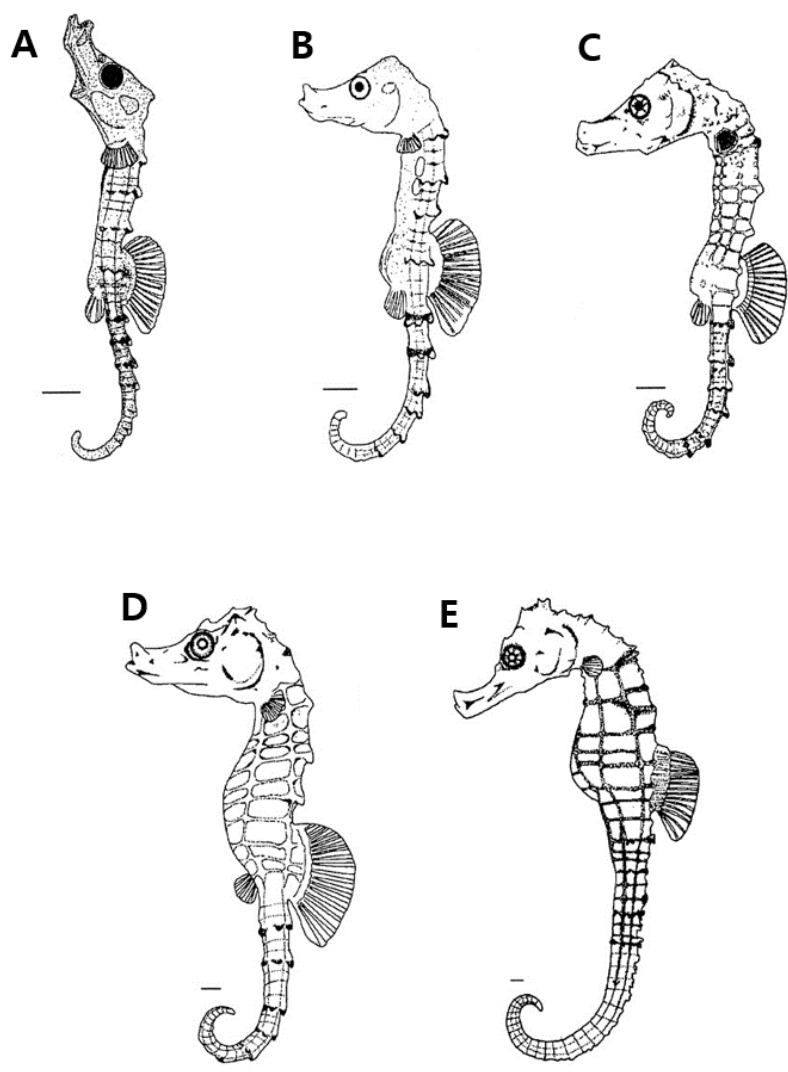

Fig. 3. Morphological development of the larvae and juvenile of Hippocampus $\boldsymbol{k u d a}$. A, newborn larvae $7.89 \mathrm{~mm}$ in SL; B, 4 days after bearing, $8.24 \mathrm{~mm}$ in SL; C, 12 days after bearing, $10.0 \mathrm{~mm}$ in SL; D, 21 days after bearing, $13.4 \mathrm{~mm}$ in SL; E, 41 days after bearing, $17.4 \mathrm{~mm}$ in SL. Scale bars $=1.00 \mathrm{~mm}$.

snout was similar to that of adult fish, showing a feeding pattern of sea horses taking in prey by sucking seawater with the mouth (Fig. 3C).

On the 21 days after bearing, larvae were 12.1-14.8 SL mm (mean $13.4 \pm 1.90 \mathrm{~mm}, \mathrm{n}=10$ ), and the thorns on the upper part of the head and back were elongated, and the black vesicles deposited on the head and gill lid were widely deposited (Fig. 3D).

On the 41 days after bearing, juveniles were 17.1-17.8 SL mm (mean 17.4 $\pm 0.49 \mathrm{~mm}, \mathrm{n}=10$ ), and the black vesicles deposited on the fins of each part were more intensely deposited in the lower part and were evenly distributed overall. The five black radial strips formed in the eyes

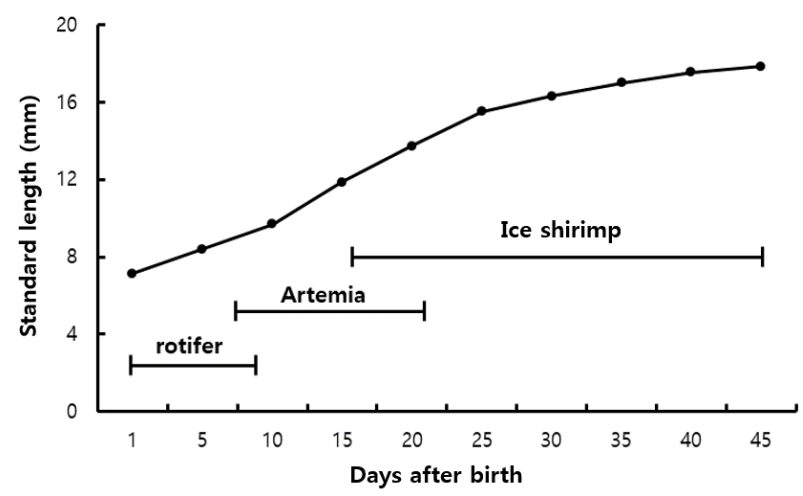

Fig. 4. The growth of standard length of the larvae and juvenile of Hippocampus kuda by days birth.

were irregularly colored depending on the individual, and the thorns formed around the eyes were $2-3$, with the ends sharply divided, and overall external morphology and number of body's bony plate rings are $11+33-36$. And the number of fin rays is $15-18$ dorsal fins and $13-14$ pectoral fins, which are the same as those of adult fish (Fig. 3E).

\section{Growth of larvae and juveniles}

Growth changes were observed from immediately after bearing to 45 days. As a result, larvae started to ingest rotifer immediately after bearing and showed a moderate growth until 10 days after bearing. As the mouth developed, the intake of the Artemia larvae became active and showed rapid growth until 25 days after bearing. After the reduction of the supply of Artemia and the sequential supply of small ice shrimps, the growth was moderate until 45 days after bearing (Fig. 4).

\section{DISCUSSION}

Seahorse is a coastal sedentary fish that is known to have a spouse in the same habitat, but molecular biological considerations for phylogenetic classification suggest that many interspecies crosses occur, necessitating reconsideration of taxonomic criteria (Vincent \& Sadler, 1995; Lourie et al., 1999b). It is a species that is difficult to classify among species because the development of larva and juve- 
niles period is similar. On the other hand, it has a phylogenetically close relationship with the Syngnathidae fish, which is a closely related species. However, their larva and juveniles are easy to be distinguished from those of other fishes because they display external characteristics close to the adult fishes immediately after bearing (Gill, 1905; Mi et al., 1998).

Generally, the number of individuals per hatch is known to be about $100-300$, and the number of individuals per hatch of $H$. kuda was found to be 70 . In the case of seahorses giving birth to a relatively small number of individuals, H. zosterae and Hippocampus give birth to 69 (Strawn, 1958 ) and 38 , respectively, which are more or similar, indicating that the size of the nursery pouch will be an important factor in determining whether the number of bearing larva and juveniles is limited (Masonjones, 1997).
When compared with the size immediately after bearing with seahorse belonging to the same genus, the larva and juveniles immediately after bearing of $H$. kuda were 6.97$8.81 \mathrm{~mm}$ (mean $7.12 \mathrm{~mm}, \mathrm{n}=10$ ), the SL of $H$. barbouri was $8.82-10.3 \mathrm{~mm}, H$. kuda was $6.66-8.01 \mathrm{~mm}, 7.0 \mathrm{~mm}$ (Mi et al., 1998), H. fuscus was $7.50 \mathrm{~mm}$, H. whitei 8.50 mm (Vincent, 1990), the SL of Hippocampus was 11.6$15.8 \mathrm{~mm}$, H. subelongatus $11.3 \mathrm{~mm}$ (Payne \& Rippingale, 2000), H. abdomimalis $20.0 \mathrm{~mm}$ (Young, 1926), which were larger than or equal to that of $H$. barbouri and larger than H. kuda but smaller than Hippocampus, showing differences (Table 1).

The number of dorsal fin rays immediately after bearing of $H$. kuda was $15-18$ and that of pectoral fins was 8. Table 1 shows the results of the comparison with Seahorse belonging to the same genus.

Table 1. Comparison of bearing larvae size of morphological characters among species of genus Hippocampus

\begin{tabular}{|c|c|c|c|c|c|}
\hline Species & $\begin{array}{c}\text { Newly bearing of } \\
\text { larvae size, mm (mean) }\end{array}$ & $\begin{array}{l}\text { Dorsal fin } \\
\text { rays }\end{array}$ & $\begin{array}{l}\text { Pectoral fin } \\
\text { rays }\end{array}$ & $\begin{array}{l}\text { Rings } \\
\text { trunk+tail }\end{array}$ & Authors \\
\hline \multirow{3}{*}{ Hippocampus kuda } & $6.97-8.81(7.12)$ & $15-18$ & $13-14$ & $11+33-36$ & Present study \\
\hline & 7.00 & $17-18$ & $15-18$ & $11+34-38$ & Lourie et al. (1999b) \\
\hline & $6.66-8.01(7.59)$ & $16-17$ & 10 & $11+36$ & Koh et al. (2004) \\
\hline \multirow{2}{*}{ H. coronatus } & $11.6-15.8(13.6)$ & 14 & 12 & $10+39$ & Choi et al. 2006b \\
\hline & - & 14 & 12 & $10+38-40$ & Lourie et al. (1999b) \\
\hline H. barbouri & $8.82-10.3(9.48)$ & 17 & 14 & $11+35$ & Choi et al. (2006a) \\
\hline H. histrix & - & $15-18$ & $17-20$ & $11+33-34$ & Lourie et al. (1999b) \\
\hline H. japonicus & - & $16-17$ & 12 & $11+39$ & Lourie et al. (1999b) \\
\hline H. trimaculatus & - & $18-22$ & $16-19$ & $11+38-43$ & Lourie et al. (1999b) \\
\hline H. fuscus & 7.50 & - & - & - & Vincent (1990) \\
\hline H. whitei & 8.50 & - & - & - & Vincent (1990) \\
\hline H. subelongatus & 11.3 & - & - & - & Payne \& Rippingale (2000) \\
\hline H. abdomimalis & 20.0 & - & - & - & Young (1926) \\
\hline
\end{tabular}


In the case of larva and juveniles immediately after bearing of seahorse, each fin and body's bony plate ring have grown close to integer (Mi et al., 1998), and the number of dorsal fin rays, the number and shape of body's bony plate ring for interspecies classification are very useful as the classification traits (Okiyama, 1988; Kanou \& Kohno, 2001). On the 12 days after bearing, the number of body's bony plate ring of the top of rings trunk were 11, on the tail of them were 33-36 in H. kuda, seahorse belonging to the same genus was similar, 11 and 36, and Hippocampus had 10, 38-40 (Lourie et al., 1999b), 10, 39 (Choi et al., 2006b), showing that the number of body's bony plate ring on the trunk was more than that on the tail. H. histrix had 11, 33-34 (Lourie et al., 1999b), H. mohnikei had 11, 39 (Lourie et al., 1999b), H. trimaculatus had 11, 38-43 (Lourie et al., 1999b), and the number of body's bony plate ring on the trunk was the same, and the number of body's bony plate ring on the tail was similar or smaller (Table 1).

To summarize the results of this study, H. kuda was identified as a species that give birth to as few as 70 individuals among seahorses and showed the difference from a closely related species in the size of bearing larva and juveniles and the number of body's bony plate ring and thus, we could obtain basic data for species identification.

The dorsal fin basin is described by Lourie et al. (1999a) reported 17-18, but the number of domestic $H$. kuda and philippines $H$. kuda were $15-18$ and 16-17, respectively. The number of the body was the same as that of the Philippines, and the pectoral fins were 13-14 in domestic and 10 in the Philippines. This result seems to be different according to the distribution, and taxonomic studies will be needed in the near future.

Recently, as the demand for seahorse as an ornamental organism and the demand for a herbal medicine material have increased in Asia, a rapid decrease in resources is expected, and its value is gradually increasing as protective rearing of fish resources in each country. Therefore, it is necessary not only to acquire the basic data of early breeding for artificial breeding and breeding technology of Seahorse, but also to study the early life history for habitat protection and species preservation.

\section{REFERENCES}

Adams MB, Powell MD, Purser GJ (2001) Effect of acute and chronic ammonia and nitrite exposure on oxygen consumption and growth of juvenile big bellied seahorse. J Fish Biol 58:848-860.

Chyung MK (1977) The Fishes of Korea. Ilji-sa Publishing Co., Seoul, p 727.

Choi YU, Jung MM, Kim SC, Kim JW, Lee JU, Lee YH, Rho S (2006a) Morphological development, growth and survival of barbour's seahorse, Hippocampus barbouri. Korean Soc Oceanogr 11:124-132.

Choi YU, Rho S, Jung MM, Lee YD, Noh GA (2006b) Parturition and early growth of crowned seahorse, Hippocampus coronatus in Korea. J Aquac 19:109-118.

Foster SJ, Vincent ACJ (2004) Life history and ecology of seahorses: Implications for conservation and management. J Fish Biol 65:1-61.

Gill T (1905) The life history of the sea-horses (Hippocampids). Proc US Natl Mus 28:805-814.

Hilomen-Garcia GV, Reyes RD, Garcia CMH (1999) Tolerance and growth of juvenile seahorse Hippocampus $\mathrm{ku}$ $d a$ exposed to various salinities. Aquaculture 122:21-25.

Kanou K, Kohno H (2001) Early life history of a seahorse, Hippocampus mohnikei, in Tokyo bay, Japan. Ichthyol Res 48:361-368.

Kim IS, Choi Y, Lee CL, Lee YJ, Kim BJ, Kim JH (2005) Illustrated Book of Korean Fishes. Kyo-Hak Publishing, Seoul, pp 106-112.

Koh JR, Kim DH, Yun SJ, Oh TY (2004) Early life history and rearing of the yellow seahorse Hippocampus kuda (Teleostei:Syngnathidae). Korean J Ichthyol 16:1-8.

Lourie SA, Foster SJ, Cooper EWT, Vincent ACJ (2004) A 
Guide to the Identification of Seahorses. Project Seahorse and TRAFFIC North America, Washington DC, p 114.

Lourie SA, Pritchard JC, Casey SP, Truong SK, Hall HJ, Vincent ACJ (1999b) The taxonomy of Vietnam's exploited seahorses (family Syngnathidae). Biol J Linn Soc 66:231-256.

Lourie SA, Vincent ACJ, Hall HJ (1999a) Seahorses: An Identification Guide to the World's Species and Their Conservation. Project Seahorse, London, p 214.

Masonjones HD (2001) The effect of social context and reproductive status on the metabolic rates of dwarf seahorses (Hippocampus zosterae). Comp Biochem Physiol Part A: Mol Integr Physiol 129:541-555.

Masonjones HD (1997) Relative parental investment of male and female dwarf seahorses, Hippocampus zosterae. Ameri Zool 37:114.

Masonjones HD, Lewis SM (1996) Courtship behavior in the dwarf seahorse, Hippocampus zosterae. Copeia 1996: 634-640.

Mi PT, Kornienko ES, Drozdov AL (1998) Embryonic and larval development of the seahorse Hippocampus kuda, Rus J Mar Biol 24:325-329.

Myers GS (1979) A freshwater seahorse. Pac Kisc 32:30-31. Okiyama M (1988) An Atlas of the Early Stage Fishes in Japan. Tokai Univ Press, Tokyo, Japan, p 1154.

Payne MF, Rippingale RJ (2000) Rearing West Australian seahorse, Hippocampus subelongatus, juveniles on copepod nauplii and enriched Artemia. Aquaculture 188: 353-361.
Scarratt AM (1995) Techniques for raising lined seahorses Hippocampus erectus. Aqua Front 3:24-29.

Strawn K (1958) Life history of the pigmy seahorse, Hippocampus zosterae Jordan and Gilbert, at Cedar Key, Florida. Copeia 1958:16-22.

Vari RP (1982) Fishes of the Western North Atlantic. Subfamily Hippocampinae, The Seahorses. Sears Foundation for Marine Research, Memoir, Yale Univ, New Haven, vol. 1, pp 173-189.

Van Look KJW, Dzyuba B, Cliffe A, Koldewey HJ, Holt WV (2007) Dimorphic sperm and the unlikely route to fertilization in the yellow seahorse. J Exp Biol 210: 432-437.

Vincent ACJ (1990) Reproductive ecology of seahorses. Ph.D. thesis, Cambridge Univ, UK, p 107.

Vincent ACJ (1996) The International Trade in Seahorses. TRAFFIC International, Cambridge, $\mathrm{p} 4$.

Vincent ACJ, Sadler LM (1995) Faithful pair bonds in wild seahorses, Hippocampus whitei. Anim Behav 50:15571569.

Woods CMC (2000a) Preliminary observations on breeding and rearing the seahorse Hippocampus abdominalis (Teleostei:Syngnathidae) in captivity. N Z J Mar Freshw Res 34:475-485.

Woods CMC (2000b) Improving initial survival in cultured seahorses, Hippocampus abdominalis Leeson, 1827 (Teleostei:Syngnathidae). Aquaculture 190:377-388.

Young MW (1926) Marine biological notes No. 2: The spawning of the seahorse. J Sci Technol 8:284. 